\title{
A strategy of gene overexpression based on tandem repetitive promoters in Escherichia coli
}

\author{
Mingji Li $i^{1}$, Junshu Wang ${ }^{1}$, Yanping Geng ${ }^{1}$, Yikui Li ${ }^{1}$, Qian Wang ${ }^{2}$, Quanfeng Liang ${ }^{1}$ and Qingsheng Qi ${ }^{1} 2^{*}$
}

\begin{abstract}
Background: For metabolic engineering, many rate-limiting steps may exist in the pathways of accumulating the target metabolites. Increasing copy number of the desired genes in these pathways is a general method to solve the problem, for example, the employment of the multi-copy plasmid-based expression system. However, this method may bring genetic instability, structural instability and metabolic burden to the host, while integrating of the desired gene into the chromosome may cause inadequate transcription or expression. In this study, we developed a strategy for obtaining gene overexpression by engineering promoter clusters consisted of multiple core-tac-promoters (MCPtacs) in tandem.

Results: Through a uniquely designed in vitro assembling process, a series of promoter clusters were constructed. The transcription strength of these promoter clusters showed a stepwise enhancement with the increase of tandem repeats number until it reached the critical value of five. Application of the MCPtacs promoter clusters in polyhydroxybutyrate (PHB) production proved that it was efficient. Integration of the phaCAB genes with the 5CPtacs promoter cluster resulted in an engineered E.coli that can accumulate $23.7 \%$ PHB of the cell dry weight in batch cultivation.

Conclusions: The transcription strength of the MCPtacs promoter cluster can be greatly improved by increasing the tandem repeats number of the core-tac-promoter. By integrating the desired gene together with the MCPtacs promoter cluster into the chromosome of E. coli, we can achieve high and stale overexpression with only a small size. This strategy has an application potential in many fields and can be extended to other bacteria.
\end{abstract}

Keywords: Promoter cluster, Tandem repeats, Gene overexpression, Metabolic engineering, Polyhydroxybutyrate

\section{Background}

The balanced flux of the whole metabolic pathway in vivo is an important issue for accumulation of the desired metabolites [1]. However, many rate-limiting steps may exist in the pathways due to weak expression of the inherent gene(s) or lack of certain essential gene (s) [2-4]. Thus, homologous or heterologous overexpression of the desired genes at the rate-limiting steps is nearly an indispensable means during metabolic engineering [5]. As a useful and easy-to-manipulate tool, the plasmid-based expression system is generally engaged to achieve this purpose [6]. However, some disadvantages make it imperfect when plasmids are employed in the pathway engineering, such as genetic instability,

\footnotetext{
* Correspondence: qiqingsheng@sdu.edu.cn

'State Key Laboratory of Microbial Technology, Shandong University, Jinan 250100, Peoples Republic of China

Full list of author information is available at the end of the article
}

structural instability and metabolic burden [7-9]. In addition, it can also become a intractable problem when the resulting plasmid is too large to be transformed into competent cells [10].

With the development of molecular biotechnology, many attempts have been made to overcome these flaws. Integration of the desired genes into the chromosome of the host seems able to circumvent these problems; and therefore many chromosome integration strategies have been developed in the past few years [11-15]. However, these approaches cannot obtain sufficient gene expression due to the inadequate strength of the promoter or the scant copy number of the target gene which was integrated into the chromosome. Repeated insertion of the target gene at multiple locations may improve its expression level to a certain degree through a site-specific chromosomal integration method developed by Kuhlman et al. [16]. Recently, Tyo

\section{() Biomed Central}


et al. developed a plasmid-free method which can achieve high copies of the desired genes by chemically inducible chromosomal evolution method (CIChE) [17]. In this method, the strain of which the desired genes together with the antibiotics had been integrated into the chromosome was evolved to obtain high copies in the locus through gradually increasing antibiotic concentration in the medium. This strategy provided an available plasmid-free method to improve stable gene expression by increasing the copy number of interest genes in the chromosome, and therefore improved the efficiency of metabolic engineering. Yet each one-copy increase of the target gene in this method, it would bring an additional antibiotic resistance gene (cat) and a homologous region of $1 \mathrm{~kb}$ in the chromosome. Therefore, there would finally produce significant amounts of the superfluous DNA sequences when enough gene copies were achieved. These DNA sequences in the chromosome may also be metabolic burden for the host [18].

To maintain high expression of the desired genes but avoid superfluous DNA sequence, we developed a strategy to improve transcription strength by constructing the promoter clusters consisted of multiple core-tacpromoters (MCPtacs) in tandem. With an ingenious design, the series MCPtacs promoter clusters were assembled via the Gibson's method [19]. The transcription strength of the MCPtacs promoter clusters was then analyzed employing the green fluorescence protein (GFP) as an indicator. Application of the MCPtacs promoter clusters in polyhydroxybutyrate (PHB) production proved its efficiency and simplicity.

\section{Results}

\section{Construction of the MCPtacs promoter clusters}

The tac promoter is nearly the strongest available promoter for metabolic engineering. However, even the tac promoter cannot satisfy the need of high expression of the desired genes in the pathway engineering, especially when they should be integrated into the chromosome. Therefore, to improve the expression of the desired genes in the chromosome, we came up with the idea of constructing a series promoter clusters by tandem repeating the strong tac promoter. Our preliminary experiments showed that the core-tac-promoter (containing $41 \mathrm{bp}$ ) possessed complete transcription function and almost the same transcription strength as the wild type tac promoter. To minimize the size of the promoter clusters for easy-to-construct, only the constitutive core-tac-promoter was then employed.

For construction, we chose the low-copy plasmid pCL1920 as the cloning vector and the $g f p$ gene (Green fluorescence protein, GFP) as the transcription strength indicator. The series constitutive MCPtacs promoter clusters were constructed in vitro following the Gibson's assembling method (See method section) [19]. The key point in our assembling process was that all the three assemble fragments had the same designed repetitive overlapping sequence, which consisted of five core-tacpromoters aligned in tandem (The 5CPtacs promoter cluster) (Figure 1). In the assemble process, every coretac-promoter could overlap with anyone in the additional assembling fragments or the same fragment (for fragment 2). Meanwhile, the $5 \mathrm{CP}$ tacs promoter cluster can be cut into any number, from one to four, of the core-tac-promoter under the action of $\mathrm{T} 5$ exonuclease and a high fidelity Phusion Host Start DNA Polymerase. Thus, plasmids with arbitrary positive integer of the core-tac-promoter were assembled [19]. As a result, ten plasmids with sequentially increased number, beginning from one, of the repetitive core-tac-promoter were obtained, and were named p1TG, p2TG, p3TG, p4TG, p5TG, p6TG, p7TG, p8TG, p9TG and p10TG, respectively.

\section{Characterization of the MCPtacs promoter clusters}

To characterize the constructed MCPtacs promoter clusters, fluorescence intensity of each construct radiated from the green fluorescence protein (GFP) was determined (Figure 2). E.coli DH5 $\boldsymbol{\alpha}$ harboring these plasmids were cultivated in LB medium. By analyzing the cell growth and relevant fluorescence of each strain, we found that the more copies of the tandem repetitive core-tac-promoter, the higher value of fluorescence/ $\mathrm{OD}_{600}$ (Figure 2A). This suggested that the transcription strength can be enhanced by increasing the tandem repeats of the core-tac-promoter. The fluorescence reached almost the maximum if the tandem repetitive number of the core-tac-promoter in the construct was five (The 5CPtacs promoter cluster). The fluorescence intensity of the 5CPtacs promoter cluster was about 4.4fold more than that of the original core-tac-promoter. The value of fluorescence/ $/ \mathrm{DD}_{600}$ to $\mathrm{OD}_{600}$ taken from the logarithmic phase was also analyzed to exclude effect of the cell growth on fluorescence enhancement. It also exhibited a stepwise enhancement for the same $\mathrm{OD}_{600}$ with the increase of tandem repeats. This result proved that the fluorescence/ $\mathrm{OD}_{600}$ enhancement was due to the increased transcription/expression eliminating the factor of increase affected by the cell growth (Figure 2B). GFP expression amounts of the MCPtacs promoter clusters in the recombinant strains was also measured via SDS-PAGE (Figure 3). Quantification of the protein band in SDS-PGAE indicated that the expression of GFP was also enhanced with the increase of the number of the core-tac-promoter until it reached five, which confirmed the results obtained by the fluorescence/ $/ \mathrm{OD}_{600}$. The gradually increased strength of the 


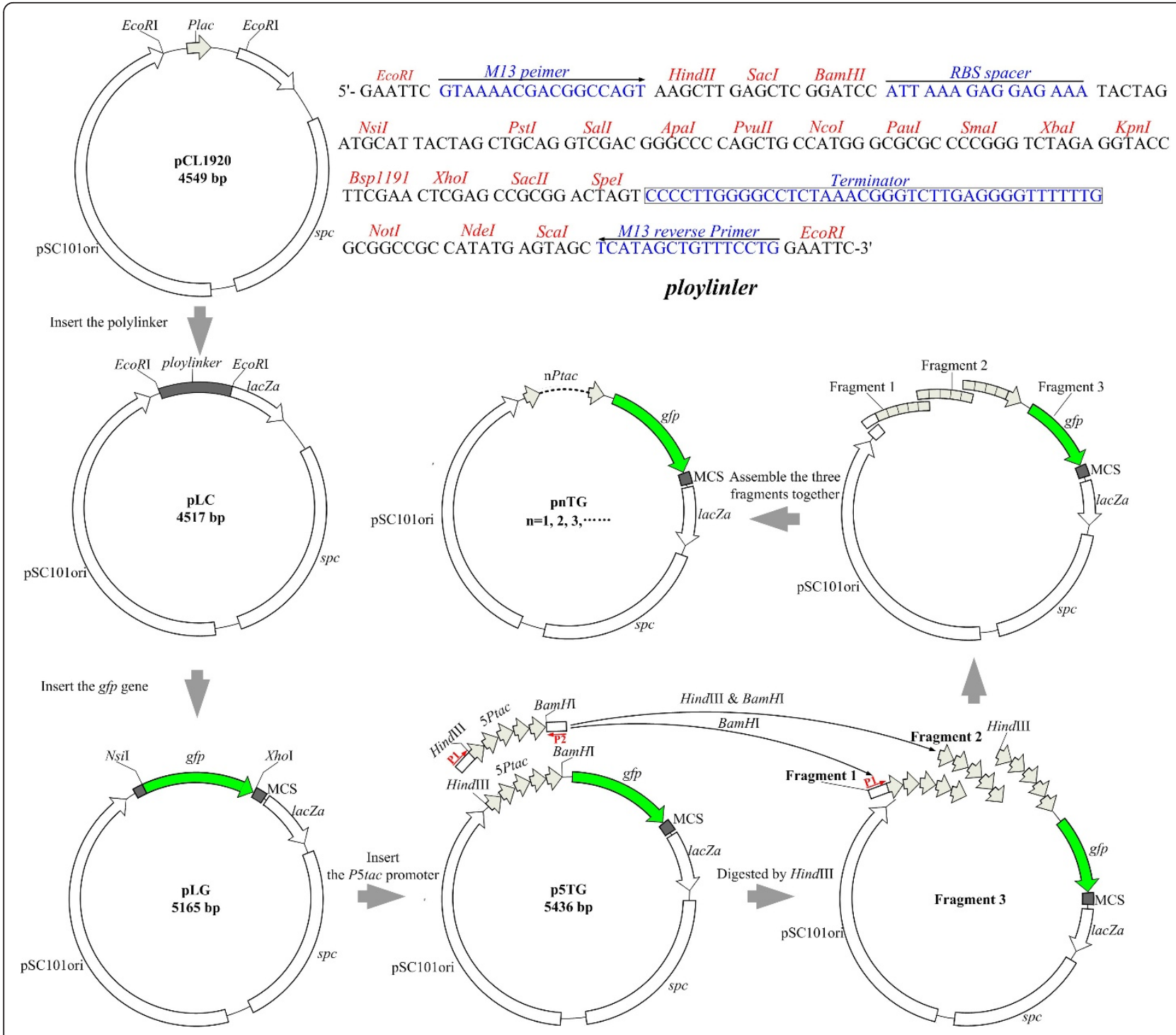

Figure 1 Construction outline of the MCPtacs promoter clusters. Fragment 5CPtacs with the flanking sequence was amplified by PCR with p5TG as the template. Fragment 1 was generated by digesting fragment 5CPtacs with BamH. Fragment 2 was digested from fragment 5CPtacs with BamHI and HindIII. Fragment 3 was linearized from the plasmid p5TG with Hindlll. Then, the three fragments were assembled together under the action of T5 exonuclease, Phusion DNA polymerase and Taq DNA ligase in the isothermal process.

MCPtacs promoter clusters indicated a potential application metabolic engineering.

\section{Application of the MCPtacs promoter cluster in PHB production}

The MCPtacs promoter cluster was demonstrated its application in metabolic engineering for PHB production in E. coli. PHB is known as an intracellular carbon/energy storage compounds and has a huge market potential due to its biodegradability. The metabolic accumulation of PHB from intermediate acetyl-CoA involves three enzymes encoded by the phaCAB operon. Generally, high copy number plasmids were used to overexpress the three enzymes to obtain a high production of $\mathrm{PHB}$ in recombinant E.coli. By expressing the phaCAB operon on pBluescript SK, a highcopy plasmid, recombinant E.coli can accumulate up to 85.8\% PHB of cell dry weight (CDW) [20]. Integration of the phaCAB genes into the chromosome increased the stability of the construct but caused dramatically reduced PHB accumulation. Our preliminary experiment showed that single copy integration of PHB operon into the chromosome can only accumulate $3.6 \%$ of cell dry weight PHB. Previous study also found that single copy integration of the phbCAB genes in the chromosome caused a very low PHB accumulation 


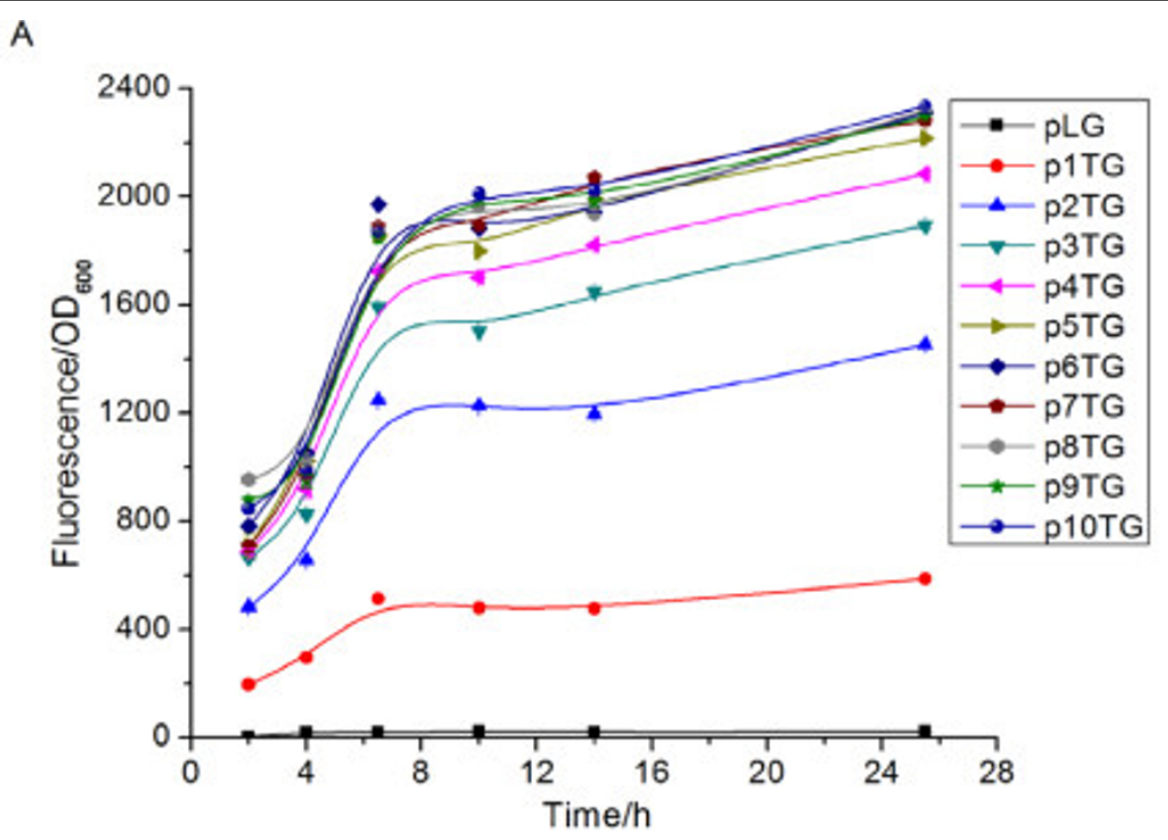

B

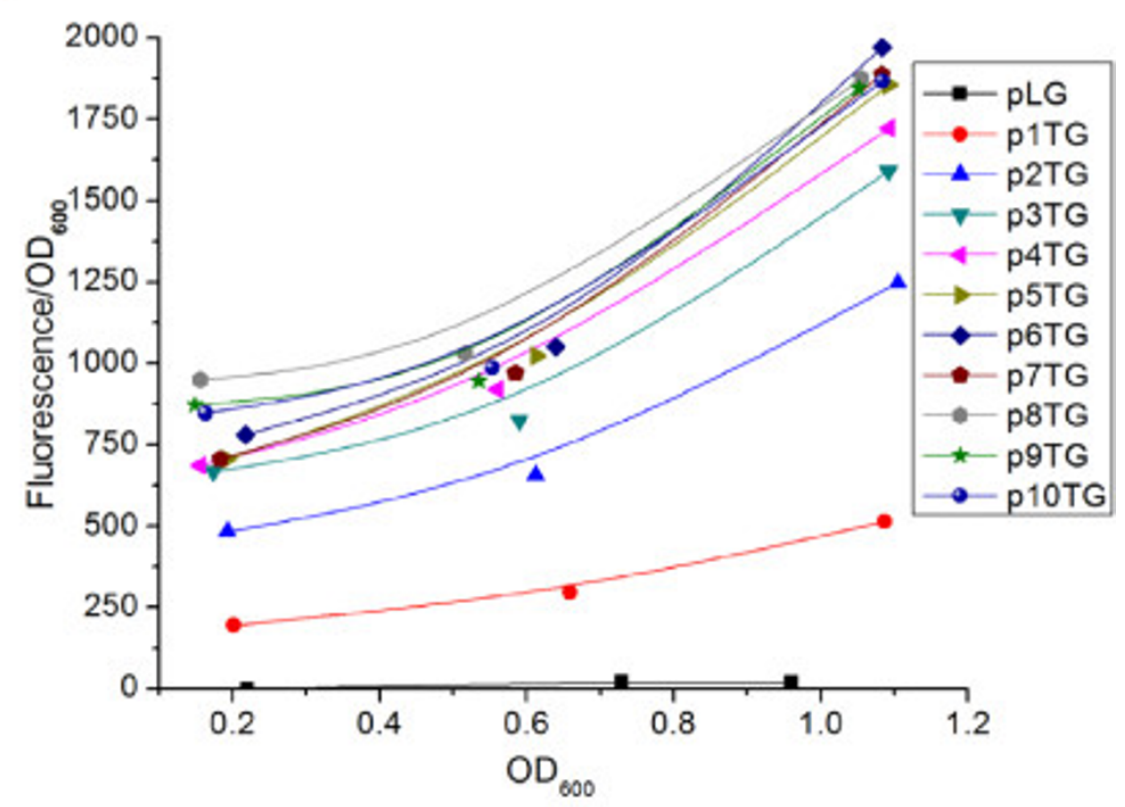

Figure 2 Determination of the transcription strength of the MCPtacs promoter clusters by fluorescence analysis. (A) The time dependent analysis of the fluorescence/ $\mathrm{OD}_{600}$ ratio; (B) The $\mathrm{OD}_{600}$ dependent analysis of the fluorescence/ $\mathrm{OD}_{600}$ ratio.

[17]. Therefore, we fused the phaCAB genes in the downstream of the 5CPtacs promoter cluster, which was found to have the strongest transcription strength, and integrated the whole cassette together with the flanking regions (4.3 $\mathrm{kb}$ in total size) into the chromosome of E. coli, resulting in the strain E. coli DH5a/ApoxB::5TPHB.

This strain was cultivated in glucose medium and found to accumulate 23.7\% PHB (wt\% of CDW) after 28 $h$ batch fermentation. The PHB accumulation was 5.6- 


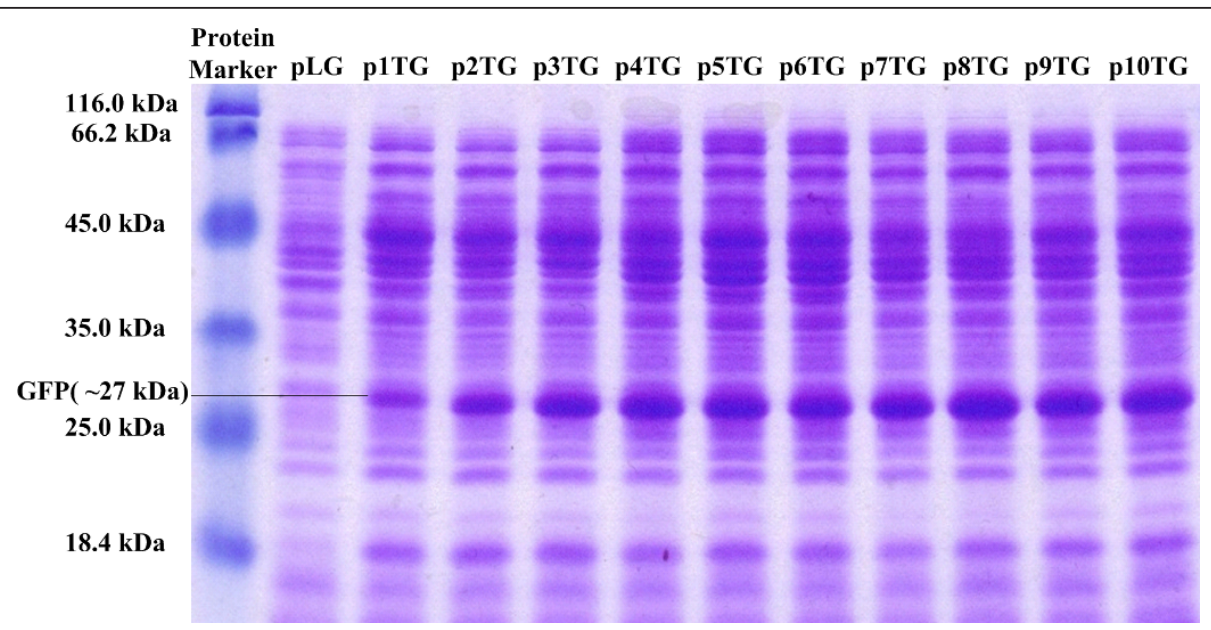

Figure 3 Determination of the GFP expression of the MCPtacs promoter clusters by SDS-PAGE. After $16 \mathrm{~h}$ cultivation, cells were harvested and lysed completely in isometric PBS. $15 \mu \mathrm{L}$ supernatant containing GFP was subjected to SDS-PAGE. GFP bands were measured with Image J software, and the areas of their corresponding peaks were used to denote the relative GFP amounts. Lane1 Protein Marker, lane2 5874.43, lane3 12432.74, lane4 14813.91, lane5 17585.91, lane6 18039.91, lane7 18487.33, lane8 17334.79, lane9 16975.38, lane10 20819.62, lane11 18758.20, lane12 20396.74.

fold more than that accumulated by the control strain E. coli DH5 $\alpha / \Delta$ poxB::1TPHB which integrated single copy core-tac-promoter. Monitoring the fermentation process, we found that consumption of glucose in E. coli DH5 / $\triangle$ poxB::5TPHB was apparently faster than that of the control strain (Figure 4). The faster glucose consummation may contribute to the faster cell growth and high PHB accumulation. In addition, we also analyzed the transcription level of the phaCAB genes integrated into the chromosome of E. coli via RT-PCR. The result showed that the transcription activity of the phaCAB

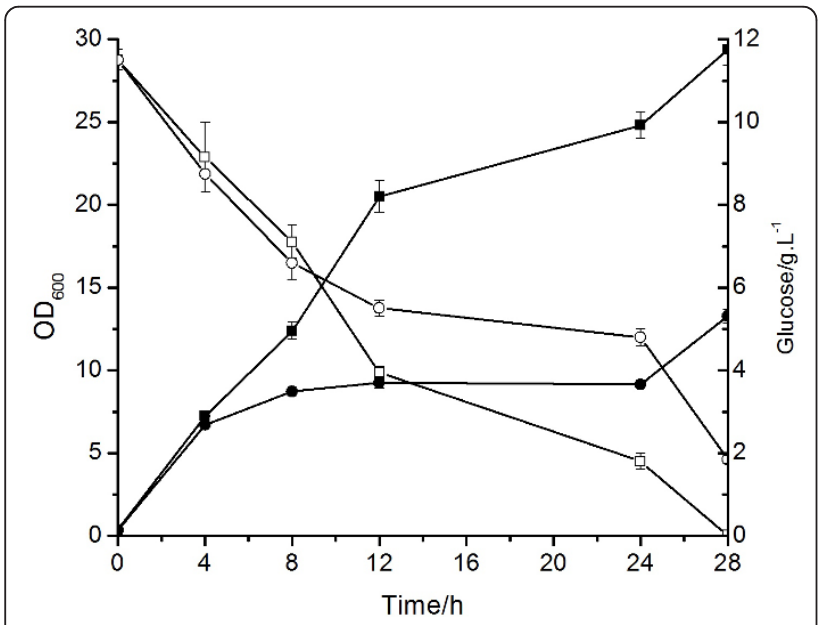

Figure 4 PHB production in the engineered $E$. coli. Glucose consumption and cell growth. Solid circles $\mathrm{OD}_{600}$ of $\mathrm{DH} 5 \alpha /$ $\triangle$ poxB::1TPHB, solid squares $\mathrm{OD}_{600}$ of $\mathrm{DH} 5 \alpha / \triangle$ poxB::5TPHB, open circles glucose consumption of DH5 $/ \triangle$ poxB::1TPHB, open squares glucose consumption of $\mathrm{DH} 5 \alpha / \triangle \mathrm{D} O \times B: 5 \mathrm{TPHB}$. genes in E. coli DH5 $\alpha / \Delta$ poxB::5TPHB was around 6fold increase in compare with the control (Table 1).

\section{Discussion}

In nature, the repetitive sequences including interspersed and tandem repetitive elements usually exist in eukaryotic genomes [21], even in promoter sequence [22]. Tandem repetitive sequences in eukaryotic genomes are involved in various regulation mechanisms of gene transcription and expression [23]. Many tandem repetitive sequences [23] and different promoters arranged in tandem $[24,25]$ are also conserved in prokaryotes. However, there has been no report that tandem repetitive promoter locates in prokaryotes genome by far. In this study, we designed and developed the promoter clusters consisted of the same core-tac-promoter arranged in tandem repeats in E.coli.

It should be pointed out that the high fidelity Phusion Host Start DNA Polymerase played an important role in assembling the MCPtacs promoter clusters with various tandem repeats of the core-tac-promoter due to its 3'-5' exonuclease activity. After digesting with restriction enzyme, there were still few unpaired residues at both 3' and 5' ends of the restriction sites at the assemble fragments. Fortunately, except for 5'-3' polymerase activity,

Table 1 Effect of the 5CPtacs promoter on the phaCAB genes transcription.

\begin{tabular}{cccc}
\hline Genes & phbA & phbB & phbC \\
\hline Relative Expression amount & $8.80 \pm 0.39$ & $6.62 \pm 0.14$ & $7.73 \pm 0.15$ \\
\hline
\end{tabular}

Expression levels of $p h b A$, $p h b B$ and $p h b C$ in $\mathrm{DH} 5 \alpha / p o x B:: 5 T$ PHB are relative to that of the control strain $\mathrm{DH} 5 \alpha /$ poxB::1TPHB. The error bars indicate the standard deviation from the mean of the three replicates 
Phusion Host Start DNA Polymerase can also remove base sequence, especially the unpaired base, from 3' end of the assemble fragment due to its high fidelity. Meanwhile, T5 exonuclease acted on the 5' end of the assemble fragments to produce partial single strand at the 3' end of the DNA molecular. Thus, the five core-tac-promoters may be also sliced one to four. Hence, a random number of the core-tac-promoter beginning from one can be constructed (Figure 1).

These promoter clusters exhibited differentially increased transcription strength compared with the original core-tac-promoter. Among them, the 5CPtacs promoter cluster was found to have strong transcription strength. Further increase in tandem repeats did not improve the transcription strength obviously. This may be due to the promoter occlusion in the process of RNA polymerases recognition and transcription $[25,26]$. In addition, the inter-promoter space may also be a considerable factor as it is necessary for E.coli RNA polymerase to occupy over a region of $80 \mathrm{bp}$ during the initiation of transcription [27]. Thus, the MCPtac promoter clusters may only accommodate limited RNA polymerases.

Due to the weak promoter strength, the existing gene overexpression methods, including plasmids and repeated integration, intended to realize this goal by increasing the copy number of the desired gene [6]. The general plasmid-based overexpression method is not stable and easy-to-lose under the conditions that antibiotics are absent $[7,17]$. The chemically inducible chromosomal evolution (CIChE) method, aiming to obtain multi-copies of the desired gene in chromosome, was confirmed to be efficient in metabolic engineering and the constructed strains were stable in the absence of antibiotics. However, taking the example of the phaCAB genes (about $6.0 \mathrm{~kb}$ including the antibiotic gene and the homologous sequence) which was integrated into the chromosome in E.coli, the total size of the integrated heterologous DNA reached $120 \mathrm{~kb}$ if 20 copies were obtained through evolution, about $2.6 \%$ of the size of $E$. coli chromosome. However, this strain can only accumulate about 18\% PHB (wt\% CDW) [17]. While our engineered strain $\mathrm{DH} 5 \alpha / \Delta$ poxB::5TPHB, of which only $4.3 \mathrm{~kb}$ heterologous DNA sequence was integrated into the chromosome, can produce $23.7 \%$ PHB (wt\% CDW). Although they found no growth difference between the engineered strain and the control, the extra synthesis of large amount of DNA should consume abundant nucleotides and much energy [28]. The integrated pha$C A B$ genes together with the $5 \mathrm{CPtacs}$ promoter cluster into the chromosome were also proved to be stable in our strain $E$. coli $\mathrm{DH} 5 \alpha$, in which $r e c A$ was deleted.

This strategy has many potential applications in the metabolic engineering. We may construct a platform for stable gene overexpression by putting a reverse selection maker under control of the 5CPtacs promoter cluster and integrating them into the chromosome of E. coli. Then, the desired genes can be used to replace the reverse selection maker through one-step homologous recombination. In addition, two or more different inducible promoters may be fused in tandem; therefore time-dependent expression can be achieved by responding different circumstances or adding corresponding inducers at different times.

\section{Conclusions}

In this study, we designed a strategy which can achieve high-level gene expression by tandem repeating the core-tac-promoter. Increasing tandem repeats of the core-tac-promoter can enhance the transcription/expression strength of the MCPtacs promoter clusters. By integrating of the $5 \mathrm{CPtacs}$ promoter cluster into the chromosome of $E$. coli, we achieved high and stable expression of the target gene with insertion of a small DNA fragment (only $4.3 \mathrm{~kb}$, taking the $p h b C A B$ genes for instance). The series of MCPtacs promoter clusters can be applied in pathway engineering of $E$. coli and extended to other bacteria.

\section{Materials and methods}

\section{Bacterial strains, plasmids and oligonucleotides}

Bacterial strains and plasmids used in this study were shown in Table 2. All oligonucleotides used in this study were summarized in Table 3 .

\section{Construction of the MCPtacs promoter clusters}

The construction of the MCPtacs promoter clusters was described as follows (Figure 1): The designed ploylinker was synthesized artificially and ligated with two EcoRI sites of plasmid pCL1920, resulting the plasmid pLC. The $g f p$ gene was amplified from the plasmid pGreenTIR by PCR using the primers $g f p-\mathrm{F}$ and $g f p-\mathrm{R}$ and cloned into the NsiI/XhoI restricted vector pLC, generating the reporter plasmid pLG. The 5CPtacs promoter cluster was synthesized in the form of five core-tac-promoters in tandem and inserted into HindIII and $\mathrm{BamHI}$ sites of the plasmid pLG to produce the plasmid p5TG. A one-step method of assembling several overlapping DNA fragments was adopted to construct the different MCPtacs promoter clusters [19]. In brief, the DNA fragment with five tandem repeats of the core-tac-promoter with flanked extensions was amplified by PCR using the primers P5tac-F and P5tac-R. Fragment 1 was obtained by digesting the resulting PCR products with $\mathrm{BamHI}$, and fragment 2 was generated by cutting with HindIII and BamHI. The plasmid p5TG was linearized by Hin$d$ III to produce fragment 3 . Then, fragment 1,2 and 3 were assembled together in vitro under the action of $\mathrm{T} 5$ 
Table 2 Strains and plasmids used in this study

\begin{tabular}{|c|c|c|}
\hline Strains and plasmids & Relevant properties & Source \\
\hline $\begin{array}{l}\text { Strains } \\
\mathrm{DH} 5 \alpha\end{array}$ & 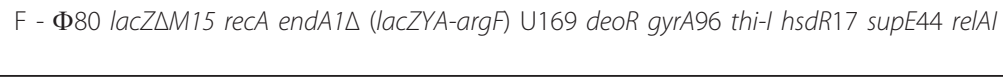 & Our laboratory \\
\hline DH5a/ApoxB::tet & $\triangle p o x B, T^{R} t^{R}$ & This work \\
\hline $\mathrm{DH} 5 \alpha / \Delta p o \times B:: 1 \mathrm{TPHB}$ & $\triangle p o x B:: 1$ tac-phaCAB & This work \\
\hline $\mathrm{DH} 5 \alpha / \triangle p o \times B:: 5 \mathrm{TPHB}$ & $\triangle p o \times B:: 5 t a c-p h a C A B$ & This work \\
\hline \multicolumn{3}{|l|}{ Plasmids } \\
\hline pGreenTIR & Plac-TIR-gfp in pUC1813, $\mathrm{Ap}^{\mathrm{R}}$ & [29] \\
\hline$\overline{p C L 1920}$ & pSC101 replication, Sp ${ }^{R}$ & [30] \\
\hline $\mathrm{pLC}$ & pLC1920-derived, ploylinker & This work \\
\hline pLG & pLC-derived, gfp gene from pGreenTIR & This work \\
\hline P1TG & pLG-derived, 1 single copy of the core-tac-promoter & This work \\
\hline p2TG & pLG-derived, 2 tandem repeats of the core-tac-promoter & This work \\
\hline p3TG & pLG-derived, 3 tandem repeats of the core-tac-promoter & This work \\
\hline$\overline{\mathrm{p} 4 \mathrm{TG}}$ & pLG-derived, 4 tandem repeats of the core-tac-promoter & This work \\
\hline p5TG & pLG-derived, 5 tandem repeats of the core-tac-promoter & This work \\
\hline p6TG & pLG-derived, 6 tandem repeats of the core-tac-promoter & This work \\
\hline p7TG & pLG-derived, 7 tandem repeats of the core-tac-promoter & This work \\
\hline p8TG & pLG-derived, 8 tandem repeats of the core-tac-promoter & This work \\
\hline p9TG & pLG-derived, 9 tandem repeats of the core-tac-promoter & This work \\
\hline p10TG & pLG-derived, 10 tandem repeats of the core-tac-promoter & This work \\
\hline pCP20 & $\mathrm{FLP}^{+}, \lambda \mathrm{cl} 857^{+}, \lambda p_{\mathrm{R}} \mathrm{Rep}^{\mathrm{ts}} ; \mathrm{Amp}^{\mathrm{R}}, \mathrm{Cm}^{\mathrm{R}}$ & [31] \\
\hline pBHR68 & pBluescript II SK-derived, phaCAB genes from Ralstonia eutropha & [32] \\
\hline pTKIP & Cloning vector, LP regions, I-Scel restriction sites, $\mathrm{Amp}^{\mathrm{R}}, \mathrm{Km}^{\mathrm{R}}$ & [16] \\
\hline PTKS/CS & p15A replication, LP regions, I-Scel restriction sites, $\mathrm{Cm}^{R}$, Tet $^{R}$ & [16] \\
\hline pTKRED & pSC101 replication, ParaBAD-driven I-Scel gene, $\lambda$-Red, Sp ${ }^{R}$ & {$[16]$} \\
\hline pTKIP-1TPHB & pTKIP-derived, 1tac-phbCAB & This work \\
\hline
\end{tabular}

exonuclease (Epicentre), Phusion Hot Start DNA Polymerase (New England Biolabs (NEB)) and Taq DNA ligase $(\mathrm{NEB})$ at $50^{\circ} \mathrm{C}$ for $15 \mathrm{~min}$. The resulting constructs containing different promoters were then transformed into competent cells and were firstly screened based on the fluorescence signal and PCR detection. The finally plasmid were confirmed by double digestion and sequencing.

\section{Fluorescence assay}

Cells harboring the MCPtacs promoter clusters were grown in $50 \mathrm{ml}$ Luria broth $(1.0 \%$ tryptone, $0.5 \%$ yeast extract, and $1.0 \% \mathrm{NaCl}$ ) at $220 \mathrm{rpm}$ and $37^{\circ} \mathrm{C}$. Samples for measurement were taken out every $2 \mathrm{~h}$ and harvested by centrifugation at $14,000 \times \mathrm{g}$ for $2 \mathrm{~min}$. After being resuspended with PBS buffer $(137 \mathrm{mM} \mathrm{NaCl}, 2.7$ $\mathrm{mM} \mathrm{KCl}, 10 \mathrm{mM} \mathrm{Na}{ }_{2} \mathrm{HPO}_{4}, 2 \mathrm{mM} \mathrm{KH} \mathrm{PO}_{4}, \mathrm{pH}$ 7.4), $200 \mu \mathrm{l}$ of bacterial culture was transferred into a 96-well plate in which $\mathrm{OD}_{600}$ and fluorescence were read with excitation at $485 \mathrm{~nm}$ and emission at $528 \mathrm{~nm}$ using a Multi-Detection Microplate Reader, Synergy HT (BioTek). For each sample, 3 repetitions were performed with PBS as a blank. Average of three repeats for the specific fluorescence and $\mathrm{OD}_{600}$ were chosen as the reference of promoter strength.

\section{Integration of the phaCAB genes into chromosome}

Integration of the phaCAB genes was executed by following Kuhlman's method [16]. In brief, the poxB gene of $\mathrm{DH} 5 \alpha$ was replaced by a tetracycline resistance gene (tet) flanked by I-SceI recognition site and 25 bp of landing pad region at each side, amplified from the plasmid pTKS/CS, and E. coli DH $5 \alpha(\Delta p o x B::$ tet $)$ was obtained. The phaCAB genes cloned from pBHR68 was inserted into $N s i$ I and $X h o$ I sites of p1TG, resulting plasmid p1TPHB. Both the plasmid pTKIP and p1TPHB were digested with HindIII and EcoRI and ligated together to create the plasmid pTKIP-1TPHB. Then, the plasmid pTKIP-1TPHB was transformed in DH5 $\alpha$ ( $\triangle$ poxB::tet)/pTKRED. In vivo recombination between landing pad regions was finished under the action of RED recombinase and the stimulation effect of I-SceI, resulting the strain DH5 $\alpha / \Delta p o x B:: 1 \mathrm{TPHB}-k a n$. The kanamycin resistance gene was eliminated with the help 
Table 3 Oligonucleotides used in this study

\begin{tabular}{|c|c|}
\hline oligonucleotides & Sequence \\
\hline$\overline{g f p-F}$ & $\begin{array}{l}\text { 5'-GCCATGCATAGTAAAG } \\
\text { GAGAAGAACTT-3' }\end{array}$ \\
\hline$g f p-R$ & $\begin{array}{l}\text { 5'-GCCCTCGAGCTATTT }^{\prime} \\
\text { GTATAGTTCATC-3' }\end{array}$ \\
\hline P5tac-F & $\begin{array}{l}5^{\prime} \text {-CCCGTCTTACTGTCGGG } \\
\text { AATTCGTA-3' }\end{array}$ \\
\hline P5tac-R & $\begin{array}{l}\text { 5'-TGCATCTAGTATTTCT } \\
\text { CCTCTITAA-3' }\end{array}$ \\
\hline phaCAB-F & $\begin{array}{l}\text { 5'-TTAATGCAT GCGACCGGCAAAGGCGCG } \\
\text { GCAGCTTCCAC-3' }\end{array}$ \\
\hline phaCAB-R & $\begin{array}{c}\text { 5'-ATTCTCGAG TCAGCCCATATGCAG } \\
\text { GCCGCCGTTG-3' }\end{array}$ \\
\hline poxB-F & $\begin{array}{c}\text { 5'-GCAGGGGGATTTGGTTC } \\
\text { TCGCATAATCGCCTTATGCCCGA } \\
\text { TGATATTCCTITCATCGGG } \\
\text { CTACGGCCCCAAGGTCCAAAC-3' }\end{array}$ \\
\hline poxB-R & $\begin{array}{l}\text { 5'-GCCACCCTITIACCTTAGCC } \\
\text { AGTITGTTITCGCCAGTCG } \\
\text { ATCACTTCATCACCGCGTC } \\
\text { TTGGCTTCAGGGATGAGGCG-3' }\end{array}$ \\
\hline \multicolumn{2}{|l|}{ RT-PCR } \\
\hline gapA-F & $\begin{array}{l}\text { 5'-AACTGAATGGCAAACT } \\
\text { GACTGGTA-3' }\end{array}$ \\
\hline gapA-R & $\begin{array}{l}\text { 5'-TTTCATTCGC } \\
\text { CTTCAGCAGC-3' }\end{array}$ \\
\hline phbA-F & $\begin{array}{l}\text { 5'-CAAGACCTGGACCT } \\
\text { GATGGAG-3' }\end{array}$ \\
\hline phbA-R & $\begin{array}{l}\text { 5'-GCCGTTCACATT } \\
\text { GACCTTGG-3' }\end{array}$ \\
\hline phbB-F & $\begin{array}{l}\text { 5'-GTGGTGTTCCG } \\
\text { CAAGATGAC-3' }\end{array}$ \\
\hline phbB-R & $\begin{array}{l}\text { 5'-CGACGAGATGTTG } \\
\text { ACGATGC-3' }\end{array}$ \\
\hline phbc-F & $\begin{array}{l}\text { 5'-CTGGACTTTG } \\
\text { CCGACAC-3' }\end{array}$ \\
\hline$\overline{p h b C-R}$ & $\begin{array}{l}\text { 5'-CGTAGTTCCAC } \\
\text { ACCAGG-3' }\end{array}$ \\
\hline The 5CPtacs promoter cluster's sequence & $\begin{array}{l}\text { TTGACAATTAATCATCGGCT } \\
\text { CGTATAATGTGTGGAATTGTG } \\
\text { TTGACAATTAATCATCGGCT } \\
\text { CGTATAATGTGTGGAATTGTG } \\
\text { GAGCTCTTGACAATTAATCAT } \\
\text { CGGCTCGTATAATGTGTGGAAT } \\
\text { TGTGTTGACAATTAATCATCGG } \\
\text { CTCGTATAATGTGTGGAATT } \\
\text { GTGTTGACAATTAATCATCGG } \\
\text { CTCGTATAATGTGTGGAATTGTG }\end{array}$ \\
\hline
\end{tabular}

of pCP20 cultivating at $42^{\circ} \mathrm{C}$ as described by Datshenko [33] and the finally strain DH5 $\alpha / \Delta p o x B:: 1 \mathrm{TPHB}$ was obtained. In the same way, the strain DH5a/ $\triangle p o x B:: 5$ TPHB was constructed.

\section{PHB fermentation}

Preculture was grown overnight at $37^{\circ} \mathrm{C}, 250 \mathrm{rpm}$ in Luria broth medium supplemented with $25 \mu \mathrm{g} / \mathrm{ml}$ kanamycin. Fermentation was carried out in $250 \mathrm{ml}$ shake flask containing $50 \mathrm{ml}$ modified $\mathrm{M} 9$ medium (42.3 mM Na $2 \mathrm{HPO}_{4} \cdot 12 \mathrm{H}_{2} \mathrm{O}, 22.0 \mathrm{mM} \mathrm{KH_{2 }} \mathrm{PO}_{4}, 8.6 \mathrm{mM}$ $\mathrm{NaCl}, 18.7 \mathrm{mM} \mathrm{NH}_{4} \mathrm{Cl}, 2 \%$ extract, $1 \mathrm{mM} \mathrm{MgSO}_{4}, 0.1$ $\mathrm{mM} \mathrm{CaCl}{ }_{2}$ ) supplemented with $1.2 \%$ glucose, $0.1 \mathrm{M}$ MOPS and $25 \mu \mathrm{g} / \mathrm{ml}$ kanamycin antibiotic at $37^{\circ} \mathrm{C}$ and $250 \mathrm{rpm}$. $\mathrm{pH}$ was adjusted at 7.0 with $\mathrm{NH}_{3} \cdot \mathrm{H}_{2} \mathrm{O}$. Samples with a defined interval were harvested by 
centrifugation at $14,000 \times \mathrm{g}$ for $2 \mathrm{~min}$. The supernatant was then diluted to an appropriate concentration to measure glucose concentration using SBA-40 C (Biology Institute of Shandong Academy of Sciences). After suspending with PBS ( $\mathrm{pH} 7.4$ ), the sample cells were read at $600 \mathrm{~nm}$ for the optical density $\left(\mathrm{OD}_{600}\right)$.

\section{Analysis of PHB by GC}

The PHB content was quantitatively determined via gas chromatography (GC, Shimadzu) using a Gas Chromatography. Cultures were collected by centrifugation $(5,000 \times \mathrm{g}, 10 \mathrm{~min})$ and lyophilized overnight. Mixture of $20 \mathrm{mg}$ lyophilized cells mass with $1 \mathrm{ml}$ chloroform, 1 $\mathrm{ml}$ methanol and $15 \%(\mathrm{v} / \mathrm{v})$ sulfuric acid was boiled for

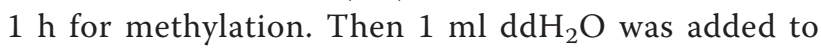
the mixture and shaken sharply for $20 \mathrm{~s}$. After the standing and layering process, the organic phase was taken out and was analyzed by GC [34].

\section{QRT-PCR assay of the phaCAB genes}

The phaCAB genes were assessed in transcription level via Quantitative Reverse Transcription PCR (QRT-PCR). Cells for mRNA preparation were cultivated for $4 \mathrm{~h}$ and then harvested. Total mRNA of DH5 $\alpha / \triangle p o x B:: 1 \mathrm{TPHB}$ and DH5 $\alpha / \Delta$ poxB::5TPHB were extracted using the RNeasy Mini Kit (Tiangen). The cDNA was amplified through reverse transcription with the total mRNA as the templates. Quantity real-time PCR (QPCR) amplification primers were designed and were listed in Table 3. The gapA gene was chosen as the control for normalization. QPCR was performed in a 96-well plate with a reaction volume of $20 \mu \mathrm{l}$ for each sample in MyiQ5768R Real-Time PCR detection system using a SYBRs Premix Ex Taq TM II (Perfect Real Time), according to manufacturer's specification (TaKaRa). The obtained data were analyzed by using the $2^{-\Delta \Delta \mathrm{Ct}}$ method described previously [35].

\section{Abbreviations}

MCPtacs: multiple core-tac-promoters; 5CPtacs: five core-tac-promoters

\section{Acknowledgements \\ This research was financially supported by a grant of the National Basic Research Program of China (2011CB707405) and grants from the National Natural Science Foundation of China (31070092 and 31170097). \\ Author details \\ 'State Key Laboratory of Microbial Technology, Shandong University, Jinan 250100, Peoples Republic of China. ${ }^{2}$ National Glycoengineering Research Center, Shandong University, Jinan 250100, Peoples Republic of China.}

\section{Authors' contributions}

$\mathrm{ML}$ carried out most of the experiments and wrote the manuscript. JW and $Y G$ are responsible for performing some experiments. $Y L$ participated in the design of this study. QW and QL assisted in data analysis and revised the manuscript. QQ conceived of the study, participated in its design, coordination and helped to draft the manuscript. All authors read and approved the final manuscript.

\section{Competing interests}

The authors declare that they have no competing interests.

Received: 12 December 2011 Accepted: 6 February 2012

Published: 6 February 2012

\section{References}

1. Varma A, Palsson BO: Metabolic flux balancing: basic concepts, scientific and practical use. Nat Biotechnol 1994, 12(10):994-998.

2. Stephanopoulos G: Metabolic engineering. Curr Opin Biotechnol 1994 5(2):196-200.

3. Balbas $P$ : Understanding the art of producing protein and nonprotein molecules in Escherichia col. Mol Biotechnol 2001, 19(3):251-267.

4. Stephanopoulos $\mathrm{G}$ : Challenges in engineering microbes for biofuels production. Science 2007, 315(5813):801-804.

5. Nielsen J: Metabolic engineering. Appl Microbiol Biotechnol 2001, 55(3):263-283.

6. Keasling JD: Gene-expression tools for the metabolic engineering of bacteria. Trends Biotechnol 1999, 17(11):452-460.

7. Friehs K: Plasmid copy number and plasmid stability. Adv Biochem Eng Biotechnol 2004, 86:47-82.

8. Lin-Chao S, Bremer H: Effect of the bacterial growth rate on replication control of plasmid pBR322 in Escherichia col. Mol Gen Genet 1986, 203(1):143-149.

9. Rozkov A, Avignone-Rossa CA, Ertl PF, Jones P, O'Kennedy RD, Smith JJ, Dale JW, Bushell ME: Characterization of the metabolic burden on Escherichia col DH1 cells imposed by the presence of a plasmid containing a gene therapy sequence. Biotechnol Bioeng 2004, 88(7):909-915.

10. Cleary JM, Rosen I, Harding NE, Cabanas DK: Recombinant DNA plasmid for xanthan gum synthesis. Merck 1987, EP0233019.

11. Hasan N, Koob M, Szybalski W: Escherichia col genome targeting I. Cre-loxmediated in vitro generation of ori- plasmids and their in vivo chromosomal integration and retrieval. Gene 1994, 150(1):51-56.

12. Martinez-Morales F, Borges AC, Martinez A, Shanmugam KT, Ingram LO: Chromosomal integration of heterologous DNA in Escherichia col with precise removal of markers and replicons used during construction. $J$ Bacteriol 1999, 181(22): 7143-7148.

13. Groth AC, Olivares EC, Thyagarajan B, Calos MP: A phage integrase directs efficient site-specific integration in human cells. Proc Natl Acad Sci USA 2000, 97(11):5995-6000.

14. Haldimann A, Wanner BL: Conditional-replication, integration, excision, and retrieval plasmid-host systems for gene structure-function studies of bacteria. J Bacteriol 2001, 183(21):6384-6393.

15. Yang HY, Kim YW, Chang HI: Construction of an integration-proficient vector based on the site-specific recombination mechanism of enterococcal temperate phage phiFC1. J Bacteriol 2002, 184(7):1859-1864.

16. Kuhlman TE, Cox EC: Site-specific chromosomal integration of large synthetic constructs. Nucleic Acids Res 2010, 38(6):e92.

17. Tyo KE, Ajikumar PK, Stephanopoulos G: Stabilized gene duplication enables long-term selection-free heterologous pathway expression. Nat Biotechnol 2009, 27(8):760-765.

18. Kolisnychenko V, Plunkett G, Herring CD, Feher T, Posfai J, Blattner FR, Posfai G: Engineering a reduced Escherichia col genome. Genome Res 2002, 12(4):640-647.

19. Gibson DG, Young L, Chuang RY, Venter JC, Hutchison CA, Smith HO: Enzymatic assembly of DNA molecules up to several hundred kilobases. Nat Methods 2009, 6(5):343-345.

20. Kang Z, Wang Q, Zhang H, Qi Q: Construction of a stress-induced system in Escherichia col for efficient polyhydroxyalkanoates production. Appl Microbiol Biotechnol 2008, 79(2):203-208.

21. Charlesworth B, Sniegowski P, Stephan W: The evolutionary dynamics of repetitive DNA in eukaryotes. Nature 1994, 371(6494):215-220.

22. Harbison $C T$, Gordon DB, Lee TI, Rinaldi NJ, Macisaac KD, Danford TW, Hannett NM, Tagne JB, Reynolds DB, Yoo J, et al: Transcriptional regulatory code of a eukaryotic genome. Nature 2004, 431(7004):99-104.

23. Kolpakov R, Bana G, Kucherov G: mreps: Efficient and flexible detection of tandem repeats in DNA. Nucleic Acids Res 2003, 31(13):3672-3678.

24. Dixon R: Tandem promoters determine regulation of the Klebsiella pneumonia glutamine synthetase ( $\mathrm{g} / \mathrm{n})$ gene. Nucleic Acids Res 1984, 12(20):7811-7830. 
25. Sneppen K, Dodd IB, Shearwin KE, Palmer AC, Schubert RA, Callen BP, Egan JB: A mathematical model for transcriptional interference by RNA polymerase traffic in Escherichia col. J Mol Biol 2005, 346(2):399-409.

26. Callen BP, Shearwin KE, Egan JB: Transcriptional interference between convergent promoters caused by elongation over the promoter. Mol Cell 2004, 14(5):647-656.

27. Schmitz A, Galas DJ: The interaction of RNA polymerase and lac repressor with the lac control region. Nucleic Acids Res 1979, 6(1):111-137.

28. Stouthamer AH: A theoretical study on the amount of ATP required for synthesis of microbial cell material. Antonie Van Leeuwenhoek 1973, 39(3):545-565.

29. Miller WG, Lindow SE: An improved GFP cloning cassette designed for prokaryotic transcriptional fusions. Gene 1997, 191(2):149-153.

30. Lerner CG, Inouye M: Low copy number plasmids for regulated low-level expression of cloned genes in Escherichia col with blue/white insert screening capability. Nucleic Acids Res 1990, 18(15):4631.

31. Cherepanov PP, Wackernagel W: Gene disruption in Escherichia col: TcR and KmR cassettes with the option of Flp-catalyzed excision of the antibiotic-resistance determinant. Gene 1995, 158(1):9-14.

32. Spiekermann P, Rehm BH, Kalscheuer R, Baumeister D, Steinbuchel A: A sensitive, viable-colony staining method using Nile red for direct screening of bacteria that accumulate polyhydroxyalkanoic acids and other lipid storage compounds. Arch Microbiol 1999, 171(2):73-80.

33. Datsenko KA, Wanner BL: One-step inactivation of chromosomal genes in Escherichia col K-12 using PCR products. Proc Natl Acad Sci USA 2000, 97(12):6640-6645.

34. Wang Q, Zhang H, Chen Q, Chen X, Zhang Y, Qi Q: A marine bacterium accumulates polyhydroxyalkanoate consisting of mainly 3hydroxydodecanoate and 3-hydroxydecanoate. World J Microbiol Biotechnol 2010, 26(6):1149-1153.

35. Livak KJ, Schmittgen TD: Analysis of relative gene expression data using real-time quantitative PCR and the 2(-Delta Delta $C(T))$ Method. Methods 2001, 25(4):402-408.

doi:10.1186/1475-2859-11-19

Cite this article as: $L i$ et al: A strategy of gene overexpression based on tandem repetitive promoters in Escherichia coli. Microbial Cell Factories 2012 11:19.

\section{Submit your next manuscript to BioMed Central and take full advantage of:}

- Convenient online submission

- Thorough peer review

- No space constraints or color figure charges

- Immediate publication on acceptance

- Inclusion in PubMed, CAS, Scopus and Google Scholar

- Research which is freely available for redistribution

Submit your manuscript at www.biomedcentral.com/submit 